\title{
Room Temperature Magnetic Transition in $\mathrm{NdCo}_{2} \mathrm{Ge}_{2}$ Na-Na XIE ${ }^{1, a}$, Yong-Quan GUO ${ }^{1, b,{ }^{*}}$
}

${ }^{1}$ School of Energy Power and Mechanical Engineering, North China Electric Power University, Beijing 102206, China

axnn@ncepu.edu.cn, byqguo@ncepu.edu.cn

${ }^{*}$ corresponding author

Keywords: $\mathrm{NdCO}_{2} \mathrm{Ge}_{2}$, Magnetic Transition.

\begin{abstract}
The magnetic properties of $\mathrm{NdCO}_{2} \mathrm{Ge}_{2}$ have been investigated. An abnormal magnetic transition occurs at room temperature. The magnetic field aligned XRD pattern implies that this phenomenon originates from the anisotrophic change by the (110) and (011) planar rotations driving by the applying magnetic field.
\end{abstract}

\section{Introduction}

The series of $\mathrm{RT}_{2} \mathrm{X}_{2}(\mathrm{R}=$ rare earth; $\mathrm{X}=$ =semiconductor) have received much attention due to their complicated low temperature magnetic properties such as metamagnetic, antiferromagnetic, Pauli paramagnetic, commensurate-incommensurate magnetic phase transition ${ }^{[1-5]}$. As for $\mathrm{NdCo}_{2} \mathrm{Ge}_{2}$, previous neutron diffraction studies were mainly focused on the low temperature magnetic properties. Two low temperature magnetic transitions have been observed in $\mathrm{NdCo}_{2} \mathrm{Ge}_{2}{ }^{[6,7]}$, one was suggested to be an antiferromagnetic transition at low temperature, and the other was suggested to be an anisotropic transition from incommensurate to commensurate. However, the room temperature magnetic properties could not be studied due to the limitation of measurement temperature $(0-250 \mathrm{~K}$ and $0-300 \mathrm{~K})$. In this study, the magnetic properties of $\mathrm{NdCo}_{2} \mathrm{Ge}_{2}$ have been systemically investigated.

\section{Experiment Methods}

The sample with a nominal composition of $\mathrm{NdCo}_{2} \mathrm{Ge}_{2}$ was prepared by arc-melting under a protective ultra-pure argon gas, and followed by annealing process at $1073 \mathrm{~K}$ for one week in an evacuated quartz tube. The purity of the raw elementary was better than $99.9 \%$. The crystal structure of $\mathrm{NdCo}_{2} \mathrm{Ge}_{2}$ was determined using powder X-ray diffractometer (Rigaku G/max 2500, using CuKa1 radiation). The temperature dependence of magnetization $(M-T)$ was measured on a SQUID magnetometer at a field of $5 \mathrm{kOe}$ in temperature range from $5 \mathrm{k}$ to $380 \mathrm{~K}$. The field dependence of magnetization $(\mathrm{M}-\mathrm{H})$ at room temperature about samples before and after aligned (aligned at a magnetic field of $0.5 \mathrm{~T}$ ) was measured with a vibrating sample magnetometer (VSM) with applying the field rang from 0 to $30 \mathrm{KOe}$, for aligned sample we measured two directions of parallel and perpendicular to the applied magnetic field.

\section{Field-cooled (FC) M-T Analysis}

The field-cooled (FC) $M-T$ curve is shown in Fig.1. Three magnetic transitions have been observed in $\mathrm{NdCO}_{2} \mathrm{Ge}_{2}$. This might originate from the exchanging interaction between the isolated Co spins or $4 \mathrm{f}$ electron spins of $\mathrm{Nd}$ with the surrounding conduction electrons. The second magnetic transition might be interpreted as a skyrmion effect induced by the topological state of Co spin 
alignment, which could lead to the magnetic anisotropy change from the multiaxial to the triangle cone.

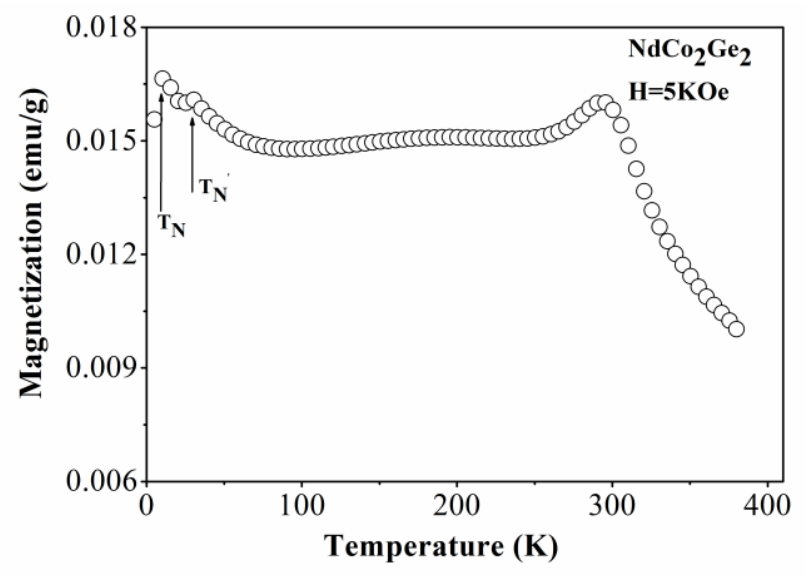

Fig.1 The Temperature Dependence of Magnetization

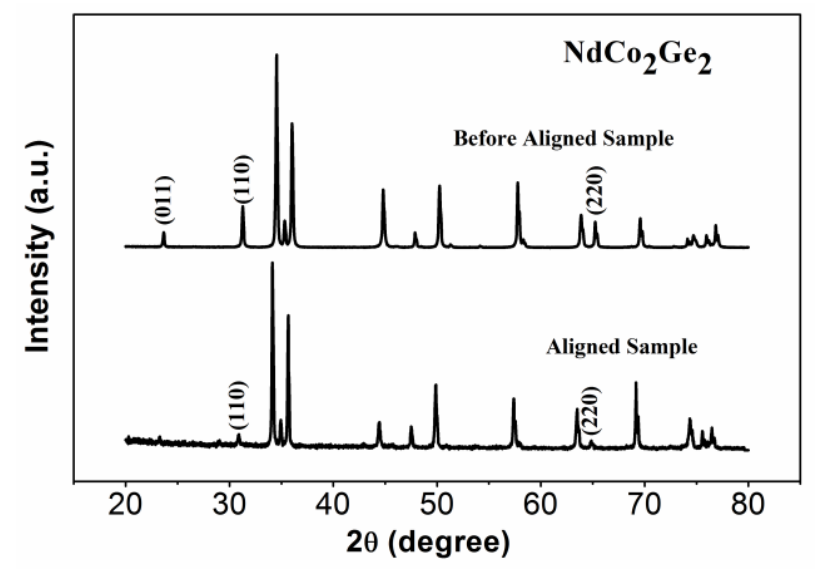

Fig.2 XRD Patterns for $\mathrm{NdCo}_{2} \mathrm{Ge}_{2}$ before and after Alignment

\section{Field Aligned X-ray Diffraction Analysis}

In high temperature regime, an anomaly magnetic transition occurs at room temperature. To understand this phenomenon, we measured XRD patterns of $\mathrm{NdCo}_{2} \mathrm{Ge}_{2}$ samples before and after

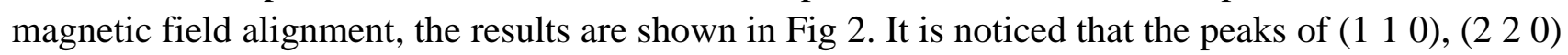
and $\left(\begin{array}{lll}0 & 1 & 1\end{array}\right)$ significantly weaken and even disappear after the field alignment process. It implies these planes might have intrinsic moments, and rotate to the direction of applied field by the driven force of the magnetic field, resulting in the magnetic anisotropy.

\section{M-H at Room Temperature}

The field-dependent magnetization of $\mathrm{NdCo}_{2} \mathrm{Ge}_{2}$ at room temperature is shown in Fig3. The curve before aligned is almost perfectly linear reaching $0.42 \mathrm{emu} / \mathrm{g}$ at $30 \mathrm{KOe}$. However, after aligned, it shows mixture of paramagnetic and ferromagnetic. The inset detailing the low field region implies the anisotropic field is in vicinity of $2.7 \mathrm{KOe}$. The figure line which represents the magnetization of $\mathrm{H}$ perpendicular to the axis is higher than the other line, then we can infer that in the sample the direction of perpendicular to $\mathrm{H}$ is more easier to be magnetized. 


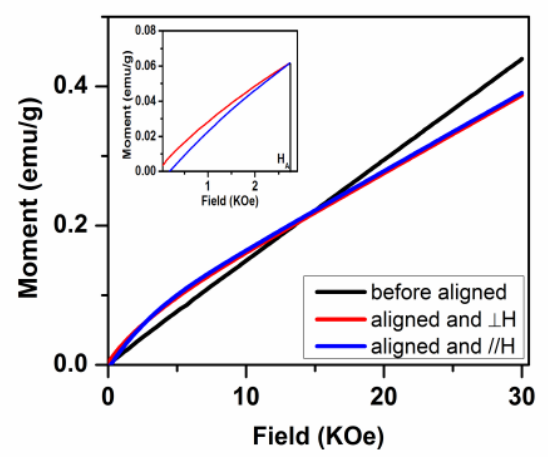

Fig.3 Magnetization vs Field

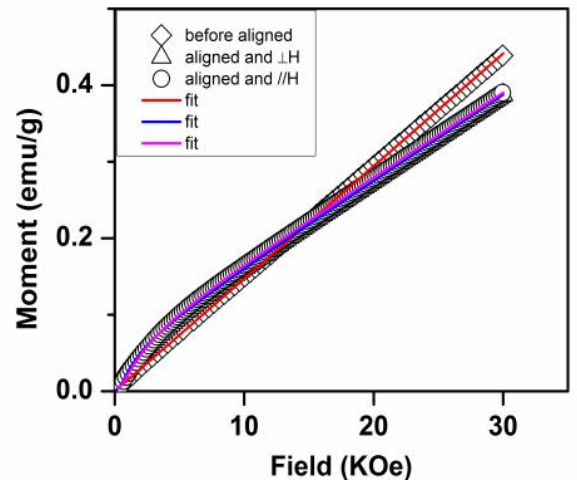

Fig.4 Fitting of Field-dependent Magnetization

\section{Fitting of M-H}

In Fig.4, we have fitted the three curves with two curtain equations. The magnetizing curve for $\mathrm{NdCO}_{2} \mathrm{Ge}_{2}$ before and after aligned follow equation 1 and 2 respectively:

$$
\mathrm{M}=\chi_{\mathrm{H}}
$$

$$
\mathrm{M}=\mathrm{Ms}(-\mathrm{a} / \mathrm{H})+\chi_{\mathrm{H}}
$$

Where $\chi$ represent the susceptibility, Ms is the saturation moment and a is a parameter related to the applied field. In equation 2, the first and second terms could be considered to be the contribution of ferromagnetic and paramagnetic, respectively. The fitting parameters are listed in Table 1 . The results imply the susceptibilities of $\mathrm{NdCo}_{2} \mathrm{Ge}_{2}$ after aligned have decreased in both of the two directions. This might result from the induction of the applied magnetic field.

Tab.1 Fitting Parameters of Magnetization vs Field at Room Temperature

\begin{tabular}{llll}
\hline \multirow{2}{*}{ Sample } & Before aligned & Aligned & \\
\cline { 3 - 4 } & & Perpendicular to $\mathrm{H}$ & Parallel to $\mathrm{H}$ \\
\hline Equations & $\mathrm{M}=\chi \mathrm{H}$ & $\mathrm{M}=\mathrm{M}_{\mathrm{s}}(-\mathrm{a} / \mathrm{H})+\chi \mathrm{H}$ & $\mathrm{M}_{\mathrm{s}} \mathrm{M}_{\mathrm{s}}(-\mathrm{a} / \mathrm{H})+\chi \mathrm{H}$ \\
Reduced Chi-Sqr & $3.64322 \mathrm{E}-6$ & $1.9672 \mathrm{E}-6$ & $6.38051 \mathrm{E}-7$ \\
Adj. R-Square & 0.99978 & 0.99982 & 0.99994 \\
$\chi(\mathrm{emu} / \mathrm{g} \cdot \mathrm{Oe})$ & $1.4715 \pm 8.865 \mathrm{E}-9$ & $1.1141 \mathrm{E}-5 \pm 1.701 \mathrm{E}-8$ & $1.0943 \mathrm{E}-5 \pm 1.073 \mathrm{E}-8$ \\
$\mathrm{M}_{\mathrm{s}}(\mathrm{emu} / \mathrm{g})$ & & $0.05613 \pm 4.3065 \mathrm{E}-4$ & $0.06585 \pm 2.87887 \mathrm{E}-4$ \\
$\mathrm{a}(\mathrm{Oe})$ & & $1410.949 \pm 27.30246$ & $1883.37029 \pm 17.0593$ \\
\hline
\end{tabular}




\section{Conclusion}

In conclusion, $\mathrm{NdCo}_{2} \mathrm{Ge}_{2}$ shows an anomaly magnetic phase transition occurs at room temperature, it might be due to the in-planes magnetic anisotropies of $\left(\begin{array}{lll}1 & 1 & 0\end{array}\right),\left(\begin{array}{lll}2 & 2 & 0\end{array}\right)$ and $\left(\begin{array}{lll}0 & 1 & 1\end{array}\right)$ planar orientations driving by the external magnetic field.

\section{Acknowledgement}

This work was supported by the national natural science foundation of China (Grant No.11274110).

\section{References}

[1] W. M. McCall, K.S.V.L Narasimhan, R.A. Butera, J. Appl. Phys. 1973, Vol.44, pp.4724.

[2] R.J. Goestsch, V.K. Anand, A. Pandey, D.C. Johnston, Phys. Rev. vol. B85, pp.054517, Feb. (2012).

[3] J.Vejpravová, J. Prokleska, V. Sechovský, J. Phys.: Conf. Ser. Vol.11, pp.143-146, (2006).

[4] P.S. Papamantellos, K. H. J. Buschow, C. Ritter, L. Keller, J. Magn. Magn. Mater. Vol.264, pp.130-146, (2003).

[5] W. Good, J. Kim, A. I. Goldman, D. Wermeille, P.C. Canfield, C. Cunningham, Z. Islam, J.C. Lang, G. Srajer, I.R. Fisher, Phys. Rev. B: Condens. Matter. Vol.71, pp. 4427, June (2005).

[6] G. André, F.B. Vigneron, A. Oleś, A. Szytuła, J. Magn. Magn. Mater., vol.86, pp.387-390, May (1990).

[7] E. Caspi, M. Kuznietz, H. Ettedgui, H. Pinto, M. Melamud, H. Shaked, Phys. Rev. vol.B57, pp.449, Jan.(1998). 